\title{
Analysis of High-rise Building Construction Technology and Quality Control Measures
}

(Hua Zhi Concrete Co., Ltd. Jinan, ShanDong, 250000, China)

\section{Features Analysis of High-rise Building}

\subsection{Great Workload in Construction}

With the passing of time, the number and scope of use of high-rise building projects have continuously expanded, and the positive impact in various places has continued to increase. This analysis holds that the great workload in construction of high-rise building can be shown from the following aspects: (1) In the process of implementation of this project, the most commonly used form is phased construction such as first phase project, the second phase project and the third phase project to consolidate its value and increase its function because the construction can't be completed within a relatively short period. (2) In the process of carrying out high-rise building projects, the various materials consumed by themselves and the amount of employed staff are very large, which will make the construction of high-rise building take long time. Only receiving a number of technical supports can get a good result.

\subsection{Higher Requirements for} Foundation Construction

Generally speaking, the requirements for the foundation construction of high-rise building are higher than that of other ordinary projects. It can not be done through the traditional methods of operation, otherwise it is difficult to get a better construction results. Combined with work experience and the current standard, this paper holds that the characteristics of higher requirements for foundation construction of high-rise building can be seen from the following aspects: (1) During the construction of high-rise buildings, the construction time of the foundation is longer than other parts. Foundation construction requires the advanced materials and construction techniques to improve the stability and reliability of foundation. In addition, massive survey analysis shall be carried on during the construction of foundation. The actual situation and characteristics of the technologies used in the construction of aboveground part shall be taken into account during the application of all technologies in foundation construction, thus a good construction result can be ensured. (2) In the process of foundation construction, foundation construction should be carried out in accordance with the principle of continuous construction. Various aspects of work should be arranged in a rational and orderly manner so as to avoid the phenomenon of improper progress of construction. For example, in the process of foundation construction, careful consideration and reasonable arrangements should be made for the depth, support, prevention and control of the foundation so as to overcome and reduce the negative impacts caused by external factors.
Abstract: In the current era of accelerating pace of urbanization, people are also in increasing demand for high-rise buildings. Because of its high height, multiple floors and large load bearing, there is a big security risk for high-rise buildings. Therefore, it is very important to control the technical points of high-rise building construction and strengthen its quality control. Therefore, this paper first analyzes the construction techniques of high-rise buildings, and then discusses the quality control strategies of high-rise buildings in order to provide some reference for improving the construction quality of high-rise buildings in our country.

Key words: High-rise building; Construction technology; Quality control; Measures

Published online: $30^{\text {th }}$ Nov, 2017

\subsection{Long Construction Period}


The construction period of high-rise building is longer than that of other ordinary buildings because the floor height is high, the consumed materials amount is large, preparation time for all work is long and various problems need to be arranged. (1) After the high-rise building project is affected by the extreme weather, it can not be dealt with by means of simple countermeasures. Instead, it should be completed through the comprehensive construction of protective measures and the effective compensation of the later period, which can minimize the threat posed to the project itself, thereby enhancing the reliability and safety of the project. (2) In the process of high-rise building construction, the technologies adopted in different stages differ sharply. The factors that will have effect on surrounding buildings and livelihood shall be considered comprehensively and sound methods shall be applied to overcome the various problems and challenges, which also results in a significant delay in the construction period. In general, the construction period for high-rise building projects is calculated on an annual basis.

\section{Technical Points of High-rise Building Construction}

2.1 Construction Technology Points of High-rise Building with Steel Structure

Reinforced steel structure occupies an important position in the current construction of the building, supporting the framework of the entire project structure, so the construction technology of reinforced steel structure is particularly important. (1) Be familiar with the design of steel structure and randomly check the number, type and quality of the steel before construction. Take mechanical test for load-bearing steel to ensure the quality of steel. (2) Steel strapping shall not only need to meet the construction quality norms, but also to meet the requirements of seismic rating of buildings.(3) Steel placing should be arranged in accordance with the design. It is strictly forbidden to change the position and type of steel. If there are special reasons, it should be approved by the relevant technical departments and design departments before implementation.

\subsection{Concrete Construction Technology} Points of High-rise Buildings
In the process of high-rise building construction, concrete construction technology and pouring quality is an important factor to ensure the quality of the project. Because the construction time of working surface is long, the concrete quality will be affected by time and weather, which will pose an obstacle to construction quality control of high-rise building. Therefore, strengthening the technical control of concrete is very important in the process of building construction. It is necessary to choose different levels of concrete according to the characteristics of high-rise buildings before construction and then carry out mix proportion test and tests on all performance of freshly mixed concrete. Then make appropriate adjustment to working mix proportion and carry out pump test if necessary to strictly control the concrete quality. In the process of concrete construction, it is necessary to take rigorous testing to cement, sand, admixtures, additives and other important control index of concrete components to ensure the quality of raw materials.

\subsection{Foundation and Measurement of High-rise Building}

In the high-rise building construction process, the measurement of the foundation of high-rise buildings is even more important. How tall the building can be depends on how deep the foundation is. It is very important to lay a good foundation for building construction. Therefore, construction units need to send professional personnel to carry out the survey of soil quality at the construction site and develop a suitable construction program according to the survey results. If the foundation soil texture is more complex and holding layers is deeper, precast piles foundation construction technology shall be used. Precast piles foundation technology has a long history in construction development, but such pile' $s$ cost is high and need to use large amount of steel materials and concrete and construction noise pollution is serious. In contrast, cast-in-place pile technology has the advantages of low cost, moderate steel and concrete usage, low noise and good adaptability to various soil bases. Foundation measurement is a very important part of the construction of the whole building. It is directly related to the structural safety of the construction project and is the prerequisite for the entire project quality assurance.
3 Quality Control Strategy of High-rise Building Construction

3.1 Quality Control of Concrete Strength in High-rise Building

(1) During the construction of high-rise buildings, we must step up the control of raw materials and make relevant adjustment strategies in time to prevent unqualified raw materials from being used in concrete construction. (2) In the process of testing the mix proportion of concrete, it is necessary to properly adjust the mixing ratio according to the water content of the gravel in order to ensure the applicability of the mix.(3) Must strictly control the mix of concrete. In the process of construction, in order to control the mix proportion of concrete, all kinds of raw materials must be tested in accordance with the requirements of standard specifications. (3) The maintenance system of high-rise buildings must be conscientiously implemented. In general, high-rise buildings mainly adopt the method of pumping concrete to carry out the construction, which not only the construction performance of concrete can be enhanced, but the construction period can also be shortened effectively. However, concrete maintenance requirements must be carefully implemented in accordance with the requirements of the standards and the detailed and enforceable maintenance system should be specified during construction in order to prevent the occurrence of insufficient strength of concrete. Concrete strength assessment requirements shall be strictly implemented and concrete specimens shall be made in strict accordance with the relevant specifications to effectively control the concrete strength.

\section{2 "Three-Lane Control" of High-rise Building}

In fact, high-rise buildings have high requirements on the continuity and scalability of construction. High-rise construction involving wide areas and with difficult operation is very prone to improper displacement, so it is necessary and important to pay attention to the three-line control of high-rise building construction. First of all, pay attention to the vertical line control because only controlling the verticality of buildings to a reasonable level can we lay a solid foundation of 
quality for high-rise building. Lay out the column network according to the number of floors and fix the edge column and corner column. In the process of installing the template, it shall be fixed along the thickness line of the outer layer. The method of hanging line is the common method to determine the perpendicularity of the vertical column. It is worth noting that the reinforcement support and concrete pouring need some technical support; Second, focus on the axis. In the transmission of high-rise building axis, the scaffolding and the construction layer need to be synchronized upward (A solid steel pipe scaffolding that provides safety protection must be $1.50 \mathrm{~m}$ above the construction face). After confirming the correctness of the axis, use theodolite for axis correction to reasonably grasp the basic control of the process line; finally, pay attention to control of elevation line. In the construction of each floor, use the hole of pre-control axis to level the leveling device, determine whether the four points are in a horizontal plane and strengthen the template support of the hole to ensure the accuracy of elevation.

3.3 Safety Construction of High-rise
Building

(1) We must control the safe construction of foundation pit supporting. Before digging the foundation pit, the foundation pit supporting plan must be designed according to the environment and soil quality of the construction site to prevent anomalies. (2) Must control the construction safety of scaffold and its protection. The scaffolding must be determined by calculation and the scaffolding plan shall be developed according to the construction process. (3) Must also control the safe construction of the template project. In the process of installing and removing the template, it is necessary to take corresponding measures according to the concrete conditions to ensure safe construction. In the process of demolishing the template, it should follow the principle that support goes before demolition. The non-load-bearing part shall be demolished first and finished products shall be protected gently and professionals shall be arranged to be responsible for regulation and protection.

3.4 Quality Control of Construction Materials
The quality of construction materials is directly related to the construction quality of the entire high-rise building, so we must strictly control the quality of construction materials. First of all, we must ensure that the selected construction materials to meet the relevant national standards, but also must meet the design requirements. Second, professionals must be responsible for the acceptance of construction materials, construction materials are prohibited from being unqualified, and substandard construction materials are forbidden. Only in this way can we eliminate the impact of unqualified construction materials on the construction quality of high-rise buildings from the source and improve the construction quality of high-rise buildings in an all-round way.

\section{References}

[1] Liu Xianghui, Discussion on High-rise Building Construction Technology and Control Measures [J].Construction Materials \& Decoration, 2016,(43):44-45.

[2] Li XiaoPeng, Brief Analysis of High Building Construction Technique and Quality Control Measures[J].Sichuan Cement, 2016,(09):247. 